Int. J. Dev. Biol. 57: 853-863 (2013)

doi: $10.1387 /$ ijdb.130302bk

\title{
Remodeling of the myocardium in early trabeculation and cardiac valve formation; a role for TGF $\beta 2$
}

\author{
BOUDEWIJN P.T. KRUITHOF*,1,2, MARIANNA KRUITHOF-DE-JULIO², ROBERT E. POELMANN ${ }^{3}$, \\ ADRIANA C. GITTENBERGER-DE-GROOT ${ }^{4}$, VINCIANE GAUSSIN ${ }^{1}$ and MARIE-JOSÉ GOUMANS ${ }^{2}$ \\ ${ }^{1}$ Cardiovascular Research Institute, Department of Cell Biology and Molecular Medicine, University of Medicine and Dentistry \\ of New Jersey, New Jersey Medical School, Newark, New Jersey, USA, ${ }^{2}$ Department of Molecular Cell Biology, ${ }^{3}$ Department \\ of Anatomy and Embryology and ${ }^{4}$ Department of Cardiology, Leiden University Medical Center, Leiden, The Netherlands
}

\begin{abstract}
Trabeculation and the formation of the leaflets of the mitral and tricuspid valves both involve remodeling of the embryonic myocardium. The nature and possible connection of these myocardial remodeling processes, however, are unclear. Therefore, we examined the morphogenesis of the early ventricular and atrioventricular (AV) myocardium and report for the first time that the formation of the early trabeculae and the positioning of the valve primordia (endocardial cushions) into the ventricular lumen are part of one continuous myocardial remodeling process, which involves the dissociation of the myocardial layers. For the endocardial cushions, this process results in delamination from the AV myocardium. The AV myocardium that will harbor the right lateral cushion is the exception and becomes positioned in the ventricular lumen by folding of the right ventricle. As a consequence, remodeling of the left and right AV myocardium occurs differently with implications for the formation of the mural leaflets and annulus fibrosis. At both the right and left side, the valvular myocardium harbors a distinct molecular phenotype and its removal from the cardiac leaflets involves a second wave of delamination. Interestingly, in the TGF $\beta 2-K O$ mouse, which is a known model for cushion and valve defects, remodeling of the early myocardium is disturbed as indicated by defective trabeculae formation, persistence of valvular myocardium, disturbed myocardial phenotypes and differential defects at left and right side of the AV canal. Based on these results we propose a new model clarifying early trabeculae formation and AV valve formation and provide new inroads for an enhanced understanding of congenital heart defects.
\end{abstract}

KEY WORDS: valve development, trabeculae, atrioventricular canal, Tbx3, TGFß2

\section{Introduction}

Cardiac disease is the leading cause of death and it has become clear that so-called acquired defects have a developmental origin. Congenital heart disease is the most common congenital defect and occurs at an estimated rate of 5\% (Pierpont et al., 2007). Heart development is characterized by complex morphogenetic processes and although a tremendous increase in understanding of the molecular mechanism has been achieved, many fundamental questions remain to be answered about the establishment of major structures including the trabeculae and the valves.

Trabeculae are sheets of myocardium that protrude into the ventricular lumen and provide most of the contractile force in the embryonic heart (Sedmera and Thomas, 1996). Trabeculation starts with the formation of early trabeculae that is thought to be initiated by endocardial outpockets (Chen et al., 2004). These early trabeculae extend and subsequently fuse contributing to the compact ventricular wall, papillary muscles, interventricular septum and conduction system. Defects in trabeculation and compaction can lead to the congenital disorder noncompaction of the ventricular wall (Jenni et al., 1999), which is closely related to

Abbreviations used in this paper: $\alpha \mathrm{SMA}, \alpha$-smooth muscle actin; AF, annulus fibrosis; $\mathrm{AV}$, atrioventricular; AVC, atrioventricular canal; cTnI. Cardiac Troponin I; E, embryonic day; EPDC, epicardium-derived cell; TGF $\beta$, transforming growth factor-beta; Wt1, Wilm's tumor-1.

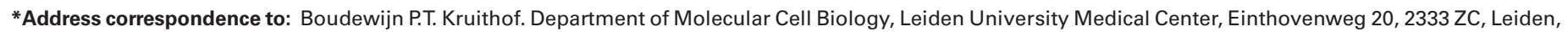
The Netherlands. Tel: +31-71-526-9264. Fax: +31-71-526-8270. E-mail: b.p.t.kruithof@lumc.nl
}

Supplementary Material (three figures) for this paper is available at: http://dx.doi.org/10.1387/ijdb.130302bk

Accepted: 21 November 2013. Final, author-corrected PDF published online: 21 February 2014.

ISSN: Online 1696-3547, Print 0214-6282 
hypertrabeculation (Chen et al., 2009). Although the morphology of the developing trabeculae has been described (Ben-Shachar et al., 1985; Challice and Viragh, 1974; Icardo and Fernandez-Teran, 1987; Sedmera et al., 2000), and the first clues about the early formation of trabeculae in zebrafish are emerging (Liu et al., 2010), it is not known how the initial early trabeculae form in mammals.

The atrioventricular (AV) valves of the heart (mitral and tricuspid) consist of leaflets that are attached to the outer myocardial wall (the mural leaflets) or to the ventricular septum (septal leaflets). The septal leaflets derive from the central cushions and the mural leaflets from the lateral cushions. These (mesenchymal) cushions develop in the AV canal (AVC). In adults, however, the valves are situated in the ventricular lumen, anchored to the annulus fibrosis and attached to the papillary muscle in the ventricle. Several issues regarding the mechanism underlying the remodeling process from cushions attached to the myocardial wall of the AVC to free-moveable leaflets in the ventricular lumen remain. 1) Previous studies report about the delamination of the valves from the ventricular wall (Lamers et al., 1995; Oosthoek et al., 1998), which raises the question how the valve primordia became relocated from the AVC myocardium to the ventricular myocardium. On the other hand, the study by De Lange et al.,(de Lange et al., 2004) indicates that the lateral cushions do not delaminate from ventricular myocardium but form on AV myocardium that protrudes into the ventricular lumen. 2) The initially formed leaflet harbors a myocardial sheet at its ventricular side. Several mechanisms, however, have been suggested to be responsible for the removal of this myocardial sheet, being the retraction towards the annulus and papillary muscle (Oosthoek et al., 1998), transformation into fibroblasts (Lamers et al., 1995), or apoptosis (de Lange et al., 2004). 3) The formation of the mural leaflets of the mitral and tricuspid valves is reported not to be intrinsically different (de Lange et al., 2004). Recently, it has been shown, however, that the left AV myocardium contributes to the left ventricle, whereas the right $\mathrm{AV}$ myocardium does not contribute to the right ventricle (Aanhaanen et al., 2009) This is likely to have consequences for the morphogenetic processes during remodeling of the left and right AV myocardium. The annulus fibrosis is a fibrous sheet separating the atrial and ventricular myocardium
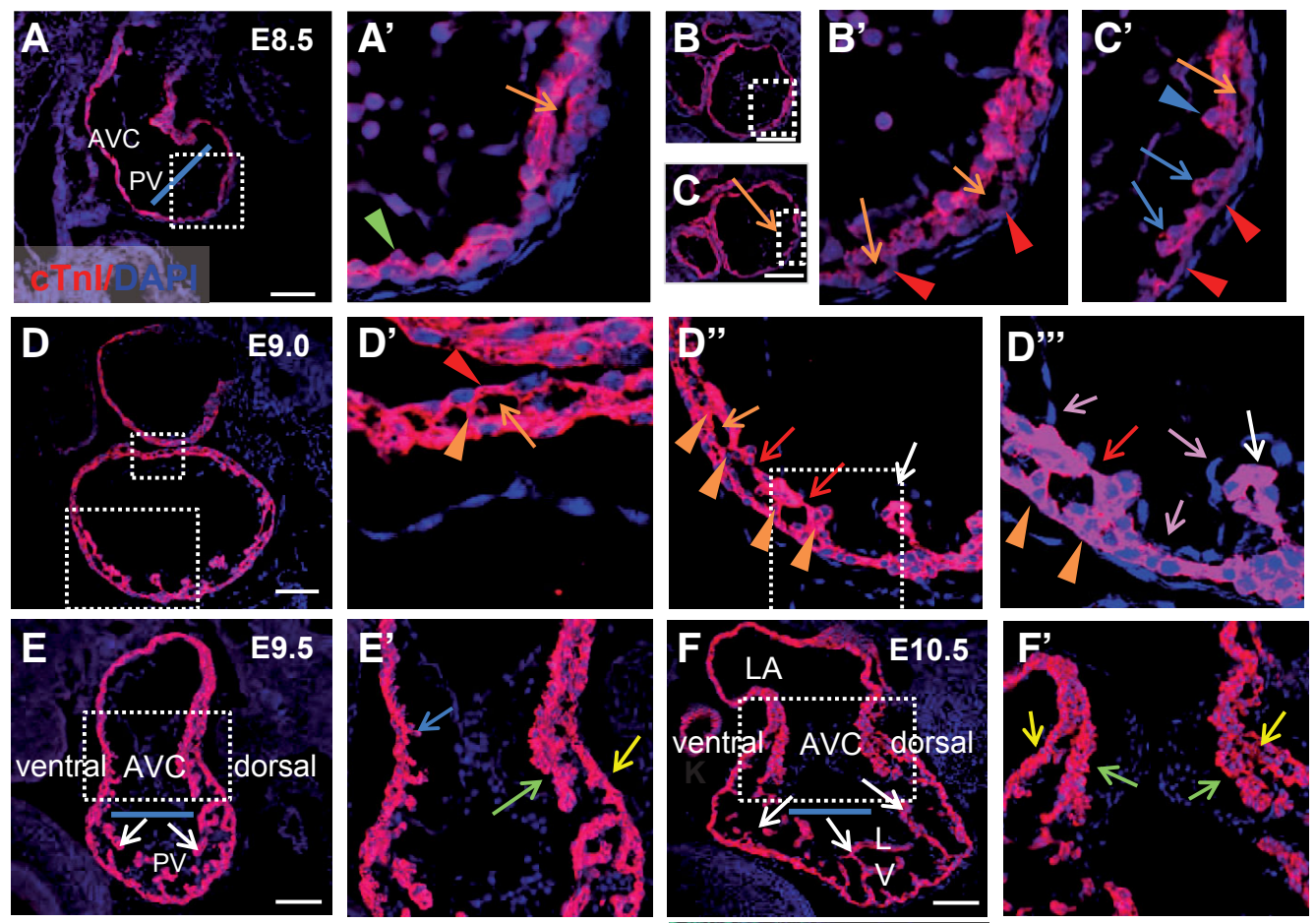

G
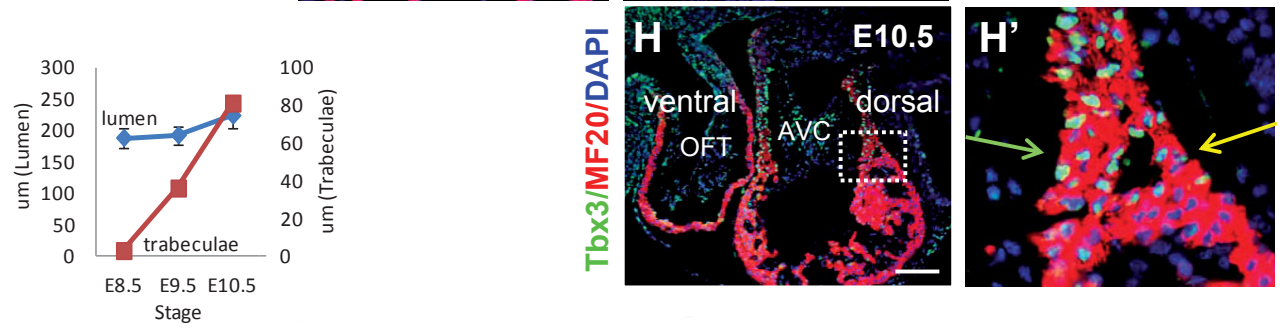

I
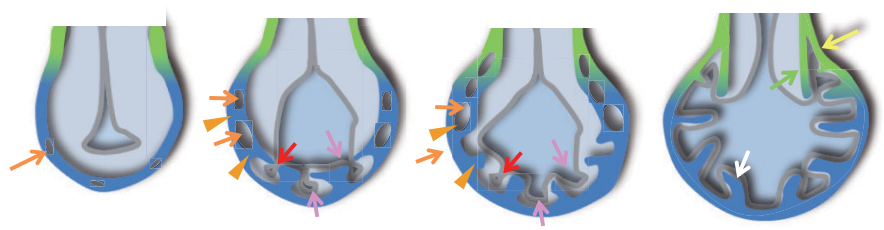

Fig. 1. The early trabeculae formation and the protrusion of the atrioventricular cushions into the ventricular lumen involve the dissociation of the myocardium. Embryonic mouse hearts are stained for cardiac troponin I (red) and nuclear marker DAPI (blue; A-F) to show the gradual dissociation of the myocardium leading to the formation of the primitive trabeculae (A-E) and protrusion of AV cushions into the ventricular lumen $(\mathbf{E}, \mathbf{F})$. The graph in $\mathbf{G}$ shows the diameter of the lumen of the ventricle (blue line measured as seen in $\mathbf{A}, \mathbf{E}, \mathbf{F}$ ), which remains the same from E8.5 to E10.5, and the length of the trabeculae (red line). Section in $\mathbf{( H )}$ is stained forTbx3 (green), MF20 (red) and DAPI (blue). (I) A schematic drawing indicating the gradual process of trabeculae formation which continues in the AVC to achieve protrusion of the AV cushion into the ventricular lumen. Blue is ventricular myocardium, whereas green is AV myocardium. For arrows see text. $L A$, left atrium; $L V$, left ventricle; OFT, outflow tract; $P V$, primitive ventricle. Scalebar: $100 \mu \mathrm{m}$. 
blocking the conduction of the electrical impulse. Disrupted formation of the annulus fibrosis results in accessory pathways of AV conductance, which can lead to pre-excitation of the ventricles (Wessels et al., 1996). The development of annulus fibrosis is tightly connected with the development of the AVC myocardium and the lateral leaflets and therefore might also be different at right and left side of the heart.

In order to get more insight in the formation of the early trabeculae and in the remodeling of the AV valve primordia, we examined the morphogenesis of the early ventricular and the AV myocardium. We propose a new model clarifying early trabeculae formation and AV valve formation, unifying apparent contradictory views on the establishment of free-moveable cardiac leaflets.

\section{Results}

\section{Dissociation of the myocardium underlies formation of the early trabeculae}

By immunofluorescent labeling of the myocardial cells we investigated the earliest trabeculae formation. At E8.5, the wall of the primitive heart consists mostly of 2 myocardial cell layers (green arrowhead in Fig. 1A'). Along the ventricular wall, particularly in the apical region of the primitive ventricle, spaces are observed in between these 2 myocardial layers (orange arrows in Fig. 1A', B', C'). In addition, protrusions of myocardial cells from the inner layer that disconnected from neighboring cells are observed into the cardiac jelly (blue arrows in Fig. 1C'), resulting in a 1-cell layered myocardial wall (red arrowhead in Fig. 1 B'-D'). These observations indicate that the inner and outer myocardial cell layers have dissociated (Fig. 1 A-D). At E9.0, the dissociation of the myocardial layers has expanded towards the basal level of the ventricle (orange arrows in Fig. 1D), although connections remain at regular intervals (orange arrowheads in Fig. 1D). The inner myocardial layer bordering the intermyocardial spaces appears also to disconnect (red arrow in Fig. 1D), which is likely to contribute to the formation of the trabecular-like protrusions as found in the apical region of the ventricle (white arrow in Fig. 1D). These trabecular structures are surrounded by endocardial cells (pink arrows in Fig. 1D). The trabecular-like protrusions form connections with each other in subsequent stages creating complex networks (white arrows in Fig. 1 D-F). Interestingly, whereas the trabecular layer of the ventricle increases from E8.5 to E10.5 (Fig. $1 \mathrm{G})$, the diameter of the lumen of the ventricle hardly changes (blue line in Fig. $1 \mathrm{~A}, \mathrm{E}, \mathrm{F}, \mathrm{G}$ ), indicating that there is outward remodeling of the outer myocardial layer (Fig. 1G). Together these results show that dissociation of the inner and outer layers of the myocardial wall from E8.5 onwards underlies the earliest formation of the trabeculae (Fig. 1I).

\section{Delamination underlies positioning of central atrioventricular cushions into the ventricular lumen}

The dissociation of the inner and outer myocardial layers that started in the primitive ventricle continues into the AVC (Fig. 1 $\mathrm{E}, \mathrm{F}, \mathrm{H}, \mathrm{I})$. In contrast to the ventricle, the dissociated inner myocardial layer of the AVC (green arrow in Fig. $1 \mathrm{E}, \mathrm{F}, \mathrm{I}$ ) remains intact and does not maintain connections with the outer myocardial layer (Yellow arrow in Fig. 1 E,F,I). This results in a split AV myocardium with a luminal AV myocardial sheet (green arrow in Fig. $1 \mathrm{E}, \mathrm{F}, \mathrm{H}, \mathrm{I}$ ) mostly supporting the endocardial cushion, that has delaminated from the outer AV myocardial sheet (yellow arrow in Fig. 1 E, F,H, I), which is continuous with the left ventricular wall. Interestingly, analyzing the expression of the AVC marker Tbx3 (de Lange et al., 2004; Hoogaars et al., 2004) showed that Tbx3 is expressed in both parts of the split AV myocardium at E10.5 (Fig. $1 \mathrm{H})$. The outer AV myocardial sheet becomes part of the ventricular wall, and as a consequence the luminal sheet supporting the AV cushion becomes positioned into the ventricular lumen (Fig. 1I).

\section{Formation of the lateral leaflets; distinct morphogical characteristics}

To be able to follow the morphological changes of the left (mitral) and right (tricuspid) AV myocardium in more detail, we specifically marked the morphological ventricular (MF20+(=high expression)/cardiac Troponin I (cTnl)+; yellow in Fig. 2,3) and AV (MF20-(=low expression)/cTnl+; green in Fig. 2,3) myocardium (see supplemental Fig. 1 for overview pictures of Fig. 2). By spe-

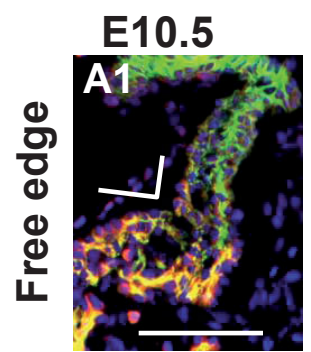

E11.5
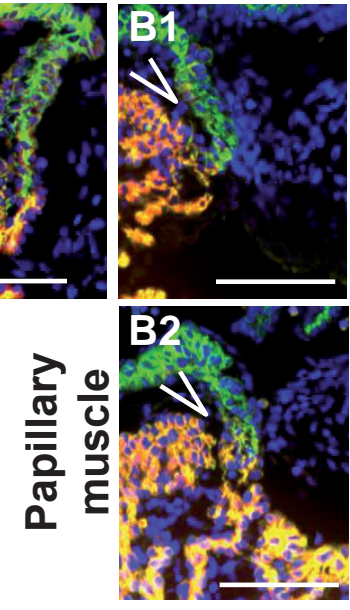

E12.5
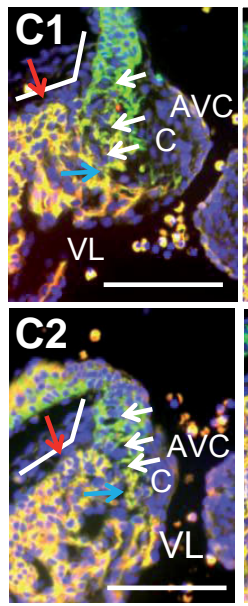

E13.5

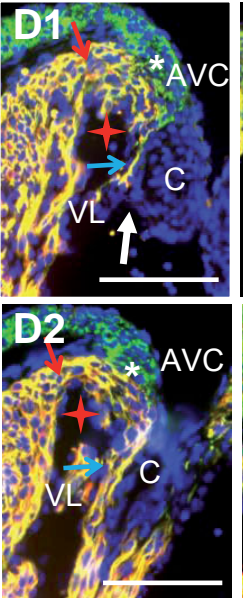

E15.5

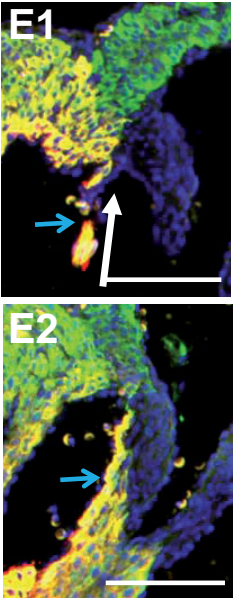

E18.5

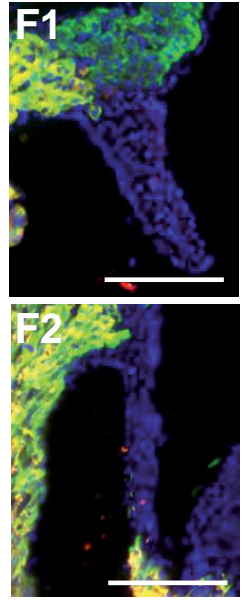

Fig. 2. Morphological changes of the left atrioventricular myocardium during valve development. MF20 (red) and cTnl (green) staining to show the MF20- (green) and MF20+ (orange/yellow) myocardium (A-F). The AV myocardium splits (white arrows panels C1,2), resulting in protrusion of cushion (C) into the ventricular lumen (VL; panels D1,2). The valvular myocardium (blue arrow) is removed from E13.5-E18.5 (D-F). Blue is DAPI. Scalebar, 100 $\mu$ m. 

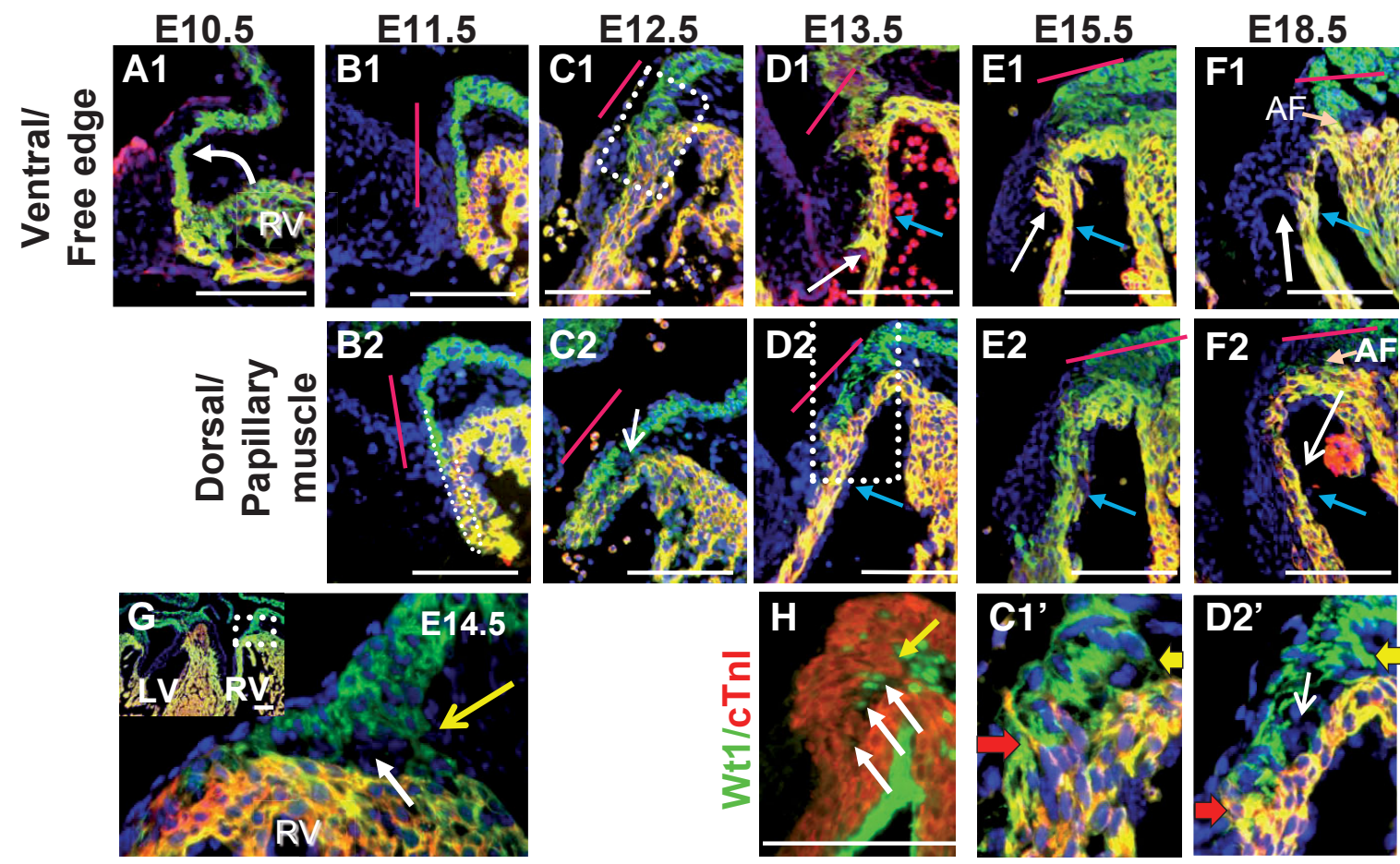

Fig. 3. Morphological changes of the right atrioventricular myocardium during valve development MF20 (red) and cTnl (green) staining to show the MF20- (green) and MF20+ (orange/yellow) myocardium (A-G). Wt1 (green) and cTnl (red) staining in panel (H). The right ventricular wall folds against AV myocardium (A,B), creating a loop of MF20- and MF20+ myocardium (B,C). Protrusions of MF20+ (red arrow) and MF20- (yellow arrow) enclose non-myocardial cells (C1,D2, G), that are Wt1+ (H). The valvular myocardium (blue arrow) at level of the free edge is removed from E13.5-E18.5 (D-F). MF20-AV myocardium changes orientation and becomes roof of annulus fibrosis (AF; red line in B-F). Blue is DAPI. Scalebar, 100 um.

cifically marking these areas, we observed clear morphological differences between left and right AV myocardium. At the left side, the angle between AV (green) and ventricular (yellow) myocardium is dynamic between E10.5 and E13.5, with a wider angle at E10.5 and E12.5, and a narrow angle at E11.5 and E13.5 (Fig. 2 A-D). At E12.5, the left AV myocardium is shorter and thicker compared with E11.5 (Fig. 2 B,C) and harbors small spaces (arrows in Fig. 2C) near the border between the MF20+ and MF20- myocardium up to the cranial border of the lateral cushion, which at this stage is positioned mostly in the AVC (Fig. 2C). At E13.5, the cushion is positioned in the ventricular lumen (Fig. 2D) and the space between the luminal sheet supporting the cushion (blue arrow in Fig. 2 C,D) and the ventricular wall (red arrow in Fig. 2 C,D) has expanded (red star in Fig. 2D), suggesting that similar to the endocardial cushions, delamination of the AV inner myocardial layer (blue arrow in Fig. 2 C,D) from the outer layer (red arrow in Fig. 2 C,D) positions the lateral cushion in the ventricular lumen. Since at E13.5 virtually no spaces are present anymore in the MF20- AV myocardium (asterix; Fig. 2D), the delamination of the AV myocardium has ceased, resulting in a more dense and structured AV myocardium. The shoulder of the left ventricle becomes located more cranially (red arrow in Fig. 2D) directing the lateral
Fig. 4. Lateral cushions form on 2 distinct types of atrioventricular myocardium. $T b \times 3$ (green), MF20 (red) and DAPI (blue) stainings show the presence of Tbx3+/MF20- (red arrow) and Tbx3+/MF20+ (white arrow) AV myocardium at both left and right side of embryonic and neonatal mouse heart. Tbx3 expression is present in left ventricular wall, but absent in right ventricular wall (yellow arrow A-F). Scalebar, $50 \mu \mathrm{m}$. left

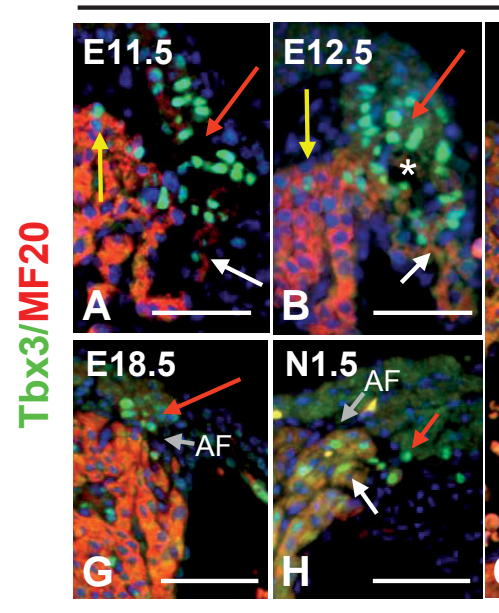

right

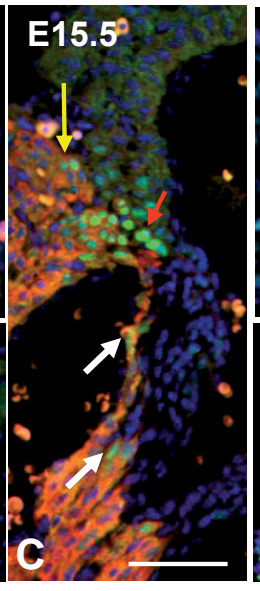


cushion even further into the ventricular lumen, resembling more the adult configuration (compare Fig. 2C with 2D).

At the right side, the ventricular myocardium has folded against the AV myocardium between E10.5 and E11.5 (compare Fig. 3A1 with 3B1-2) forming a loop consisting of MF20- (green) and MF20+ (yellow) myocardium (Fig. 3 B1-2,C1-2). At E12.5, the MF20 and $\mathrm{MF}^{2} \mathrm{O}^{+}$myocardia of this loop are separated by non-myocardial tissue, which can be clearly observed at the right dorsal side of the heart (arrow in Fig. 3C2). At E13.5, MF20+ myocardial protrusions into the MF20- myocardium (red arrow in Fig. 3D2') are present at the luminal side of this loop, whereas MF20- myocardial protrusions through the subepicardium towards the MF20+ ventricular myocardium are present at the sulcus side of this loop (yellow arrow in Fig. 3D2'), thereby enclosing non-myocardial cells (white arrow in Fig. 3 D2', G,H). At the more ventral side of the heart similar features are observed at E12.5 (Fig. 3C1'). Wilm's tumor-1 (Wt1) staining, marking epicardium-derived cells (EPDCs; (Bax et al., 2011; Perez-Pomares et al., 2002; Zhou et al., 2008)), shows that EPDCs are enclosed by these protrusions (Fig. $3 \mathrm{H}$ ). In addition, connections of these protrusions with the right ventricular
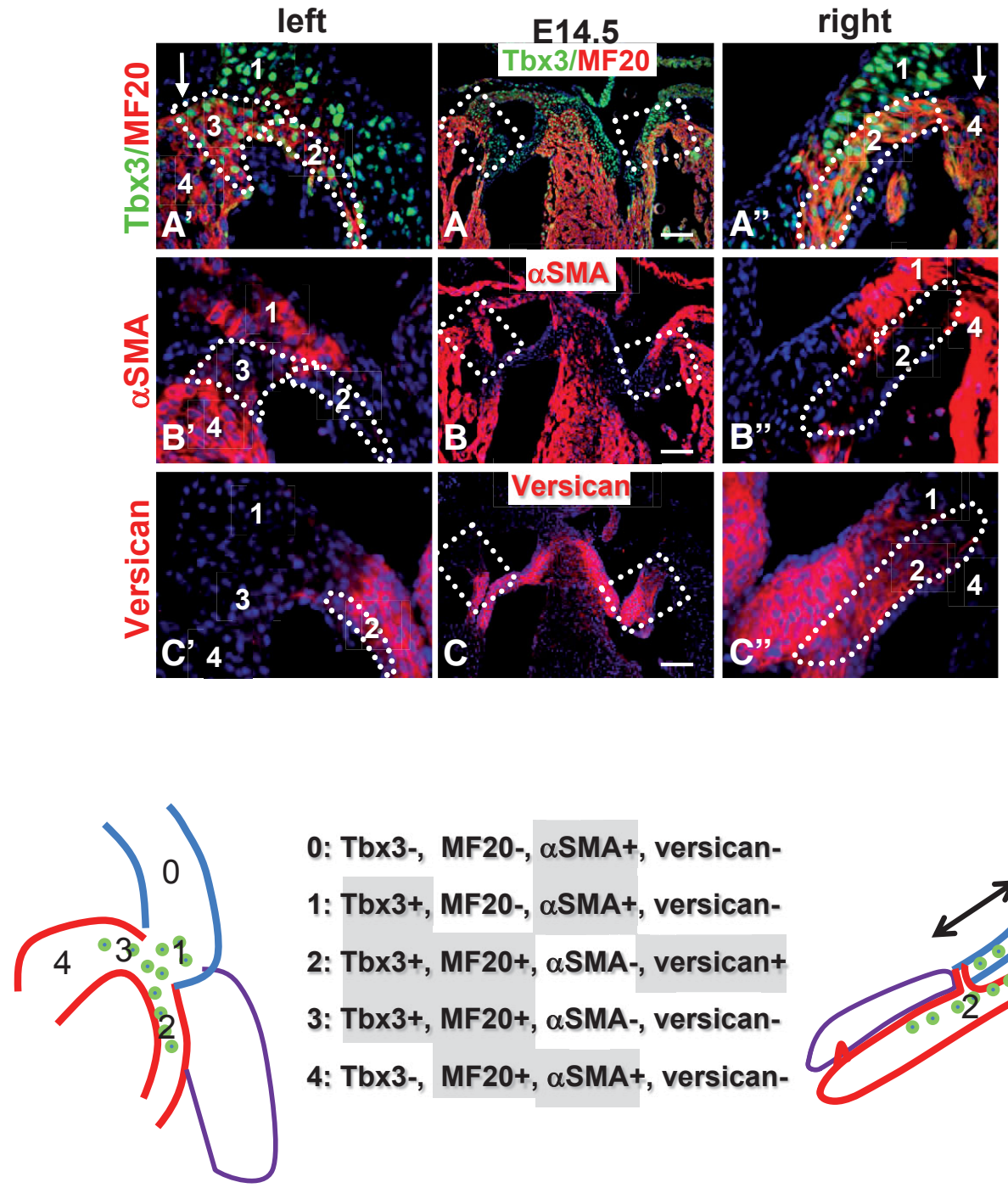

Fig. 5. Molecular characterization of myocardium in atrioventricular region. Tbx3 (green) and MF20 (red) (A) aSMA (red; B) and versican (red; C) stainings identify molecular-distinct regions. DAPI is blue. Scalebar, $100 \mu \mathrm{m}$.

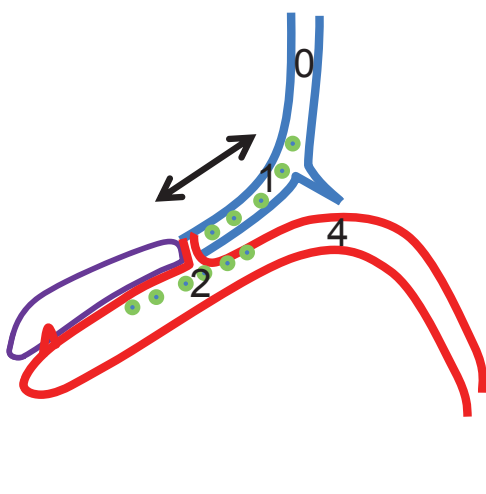

myocardium are found (yellow arrow in Fig. 3G). The protrusions of the MF20-myocardium towards the MF20+ myocardium create a shift in orientation of the MF20- part of the loop (yellow arrow in Fig. 3D2'). During development, the loop becomes repositioned on top of the right ventricular wall (red line in Fig. 3 D1-F1, 3 D2F2), thereby changing the initial cranial-caudal orientation of the $\mathrm{AV}$ myocardium, to a luminal-AV sulcus orientation (follow red line in Fig. 3). The MF20- part of the loop becomes the 'roof' of the forming annulus fibrosis, whereas the MF20+ part of the loop becomes the 'floor'.

\section{Left and right lateral cushions form on 2 distinct types of atrioventricular myocardium}

Previously, it was suggested that lateral cushions form on AV myocardium (de Lange et al., 2004). We showed in figures 2 and 3 that the lateral cushions form on and remain hinged to at least two distinct types of myocardium, MF20+ and MF20. To determine whether these types of myocardium express the AVC marker TBX3, we performed double immunostaining for Tbx3 and MF20. At both the right and the left side, relative high expression of Tbx3 (green) was present in the MF20 AVC myocardium (red arrows in Fig. 4) and a gradient of relative low expression of $\mathrm{Tbx} 3$ in the neighboring MF20+ myocardium (red) at all stages examined before birth (white arrows in Fig. 4), including the myocardial cells of the valvular myocardium and papillary muscle (Fig. 4C). After birth, Tbx3-expressing cells are still found at both sides of the formed annulus fibrosis (Fig. 4H,J). This shows that $\mathrm{Tb}^{+}{ }^{+} \mathrm{AV}$ myocardium can be divided in MF20 and $\mathrm{MF}^{2} \mathrm{O}^{+}$myocardium. Tbx3 expression is also observed in the MF20+ left ventricular wall neighboring the AVC myocardium (yellow arrow in Fig. $3 \mathrm{~A}, \mathrm{~B}$ ), but not in the right ventricular wall (yellow arrow in Fig. $3 \mathrm{D}-\mathrm{F}$ ).

MF20, TBX3, $\alpha$ SMA and versican expression define the valvular myocardium

The myocardium surrounding the lateral cushions is subdivided based on spatial ex-

pression of Tbx3 and MF20 (Fig. 5). At E14.5, Tbx3 is highly expressed in MF20 AV myocardium (region 1) and has lower expression in MF20+ valvular myocardium (region 2) and in the base of the left ventricular wall (region 3; Fig. 5A). The right ventricular wall does not express Tbx3 and therefore, region 3 is specific for the left side. The atrial myocardium bordering the AV myocardium does not express MF20 or Tbx3 (region 0) while the remainder of the ventricular myocardial wall expresses 
MF20, but is Tbx3-neg (regions 4). To further characterize the valvular myocardium molecularly, we additionally stained for $\alpha S M A$ and the extracellular matrix proteoglycan versican. Till E12.5 $\alpha$ SMA staining is found throughout the myocardium (not shown). After E12.5, the MF20+ Tbx3+ myocardium (regions 2 and 3) including the $\mathrm{Tb} 3^{+}$part of the left ventricular wall is characterized by lower $\alpha$ SMA expression (Fig. 5B). Concomitant with the decrease in the number of Tbx3+ cells during subsequent development, the $\alpha$ SMAnegative area decreases (not shown). The MF20 myocardium and most of the remaining MF20+ myocardium has higher $\alpha \mathrm{SMA}$ expression (regions $0,1,4$ ). Versican is expressed in the cushion of the lateral leaflet but also in the Tbx3+ valvular myocardium (region 2; Fig. 5C). Versican is not expressed in Tbx3+ ventricular myocardium (region 3; Fig. 4C). These expression patterns show that the AV myocardium can be divided in distinct regions with a specific molecular identity.

\section{Removal of valvular myocardium}

The removal of the MF20+ myocardial sheets from both the mitral (blue arrow in Fig. 2D) and tricuspid (blue arrow in Fig. 3D) lateral leaflets is first observed at E13.5 at the forming free edge (Fig. 2D,3D). This is complete at E15.5 for the mitral lateral leaflet (Fig. 2 D1,E1), but only at E18.5 for the tricuspid lateral leaflet (Fig. 3 D1-F1), resulting in free moveable mesenchymal leaflets.
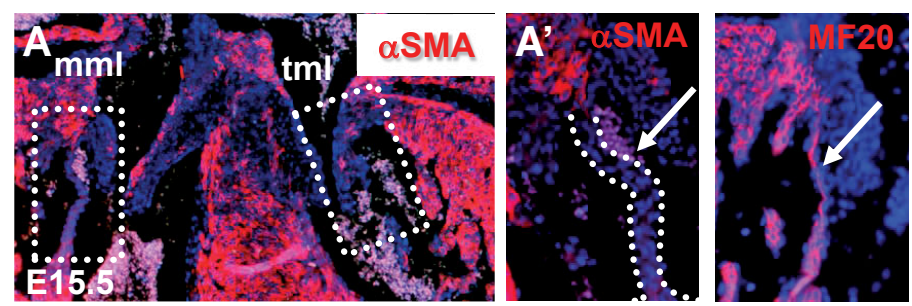

\section{Mitral mural leaflet}
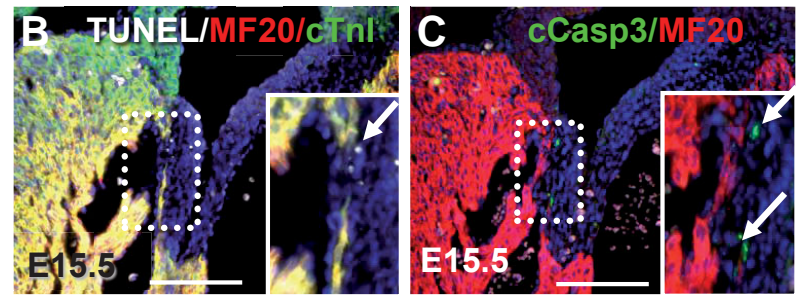

Tricuspid mural leaflet
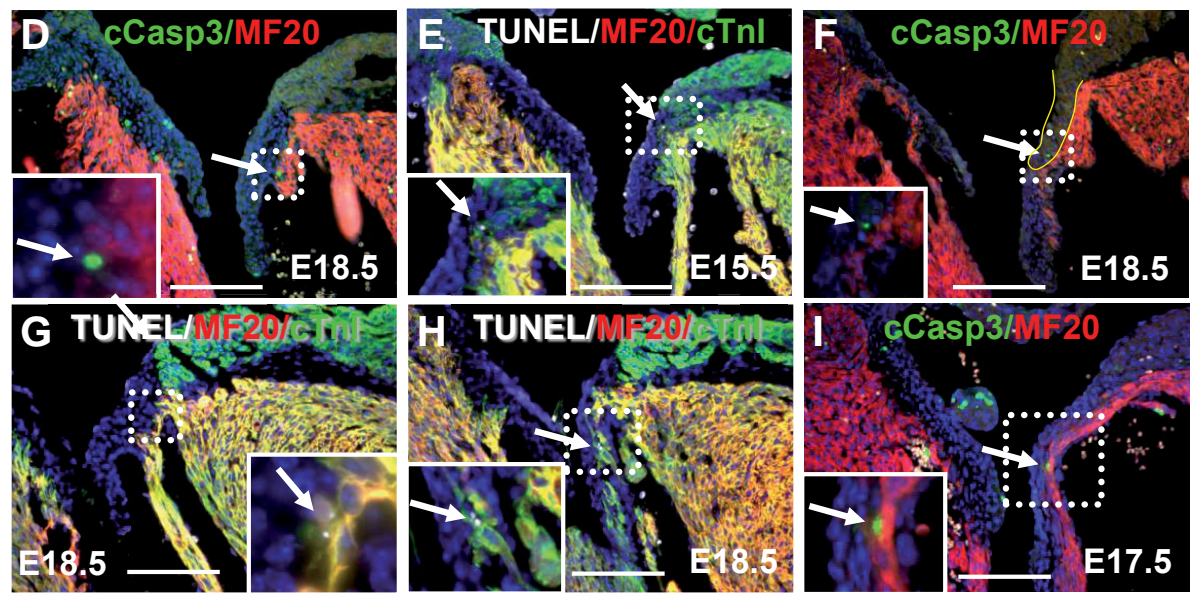

The removal of myocardium from the tricuspid lateral leaflet is preceded by MF20+ protrusions into the mesenchyme (white arrow in Fig. 3 D1,E1). At E12.5, reminiscent myocardial protrusions are found in the left lateral cushion, prior to the removal of left valvular myocardium (blue arrow in Fig. 2C1). At the level of the papillary muscles, the myocardial sleeve of the mitral lateral leaflet disappears between E15.5 and E18.5 (Fig. 2 E2,F2 and supplemental Fig. 2 C-D). The valvular myocardium at the level of the papillary muscle of tricuspid lateral leaflet, on the other hand, is still present at E18.5 (Fig. 3F2) and is removed after birth (not shown). The MF20 myocardium at the atrial side of the tricuspid lateral leaflet is repositioned from E13.5 to E18.5 as described above (red lines in Fig. 3 B1-F1,B2-F2).

Removal of myocardium can be achieved by cell death or relocation of the valvular myocardium. Relocation could be realized by the growth of the leaflets thereby relatively relocating the valvular myocardium to the distal ends of the leaflets or by detachment/ delamination of the myocardial sleeve. Relocation of the myocardium by growth of the leaflet is not likely to be involved in the removal of valvular myocardium as the growth of the leaflets is only limited (see panels in Fig. 2, supplemental Fig. 2 and the panels A1-F1 and B2-F2 in Fig. 3; note that these panels are of same magnification). The gradual lumen-to-base removal of the myocardial sleeve at the level of the free edge (white arrow in Fig.
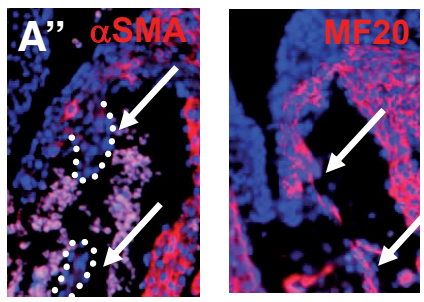

$2 \mathrm{D} 1-\mathrm{E} 1$ and $3 \mathrm{D} 1-\mathrm{F} 1)$ suggest the involvement of delamination. The myocardial sleeve differs from the trabecular myocardium by the absence of $\alpha$ SMA staining (Fig. 5B). At E15.5, when the myocardial sleeve has been mostly removed from the lateral leaflets, $\alpha$ SMA-negative, trabecula-like myocardium is found at the ventricular side of both lateral leaflets (Fig. 6A). This suggests that this myocardium was previously attached to the leaflets, supporting the hypothesis that delamination contributes to the removal of the myocardial sleeve. Apoptosis is observed in the non-myocardial cells adjacent to the myocardial sleeve (Fig. 6 B, C,D), which might be required for the detachment of the myocardial sleeve, and in the myocardial cells at the connection of MF20 and MF20+ myocardium at the tricuspid lateral leaflet (Fig.

Fig. 6. Removal of valvular myocardium by delamination and apoptosis. Neighboring sections stained for $\alpha S M A$ (red) or MF20 (red) (A) show absence of $\alpha S M A$ in myocardial sleeves adjacent to mural leaflets. TUNEL (white), MF20 (red), cTnl (green)(B,E,G,H) and cleaved caspase-3 (cCasp3; green), MF20 (red) (C,D,F,I) staining showing cell death in and surrounding valvular myocardium. DAPl is blue. $\mathrm{mml}$, mitral muralleaflet; $\mathrm{tml}$, tricuspid mural leaflet. Scalebar, $100 \mu \mathrm{m}$. 
$6 \mathrm{E}, \mathrm{F})$, suggesting that apoptosis of myocardial cells contribute to the formation of the annulus fibrosis. Furthermore, apoptosis is found in between the trabecularized valvular myocardium and the ventricular wall (Fig. 6G) and the myocardial sleeves at the level of the papillary muscle (Fig. $6 \mathrm{H}, \mathrm{I}$ ), supporting a role for apoptosis in the removal of the valvular myocardium.

\section{Myocardial remodeling defects in TGF 32 -deficient mice}

TGF $\beta 2$ is important for cushion formation (reviewed in (Kruithof et al., 2012)). Based on the model described in this study, we hy- pothesized that the cushion and valve defects seen in the TGF $\beta 2$ deficient mice (Bartram et al., 2001; Sanford et al., 1997) are related to aspects of myocardial remodeling. We observed trabeculation defects in an E9.5 TGF 32 -deficient embryos (Fig. 7 A,B), among them a lack of formation of spaces between the inner and outer myocardial layer (arrow in Fig. 7B'). In the left AV myocardium of TGF $\beta 2$-deficient mice of E11.5, on the other hand, many spaces are present between the inner and outer myocardial layers (Fig. 7D) as compared with the wt (Fig. 7C), Morphologically, both right and left AV myocardium are longer and less compact in TGF $\beta 2$ -
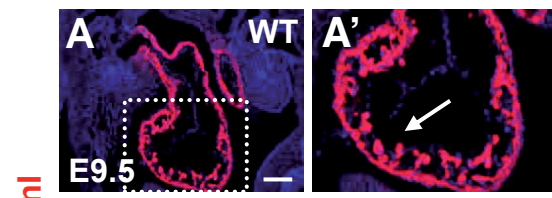

৩ B TGF $\beta 2 K O$
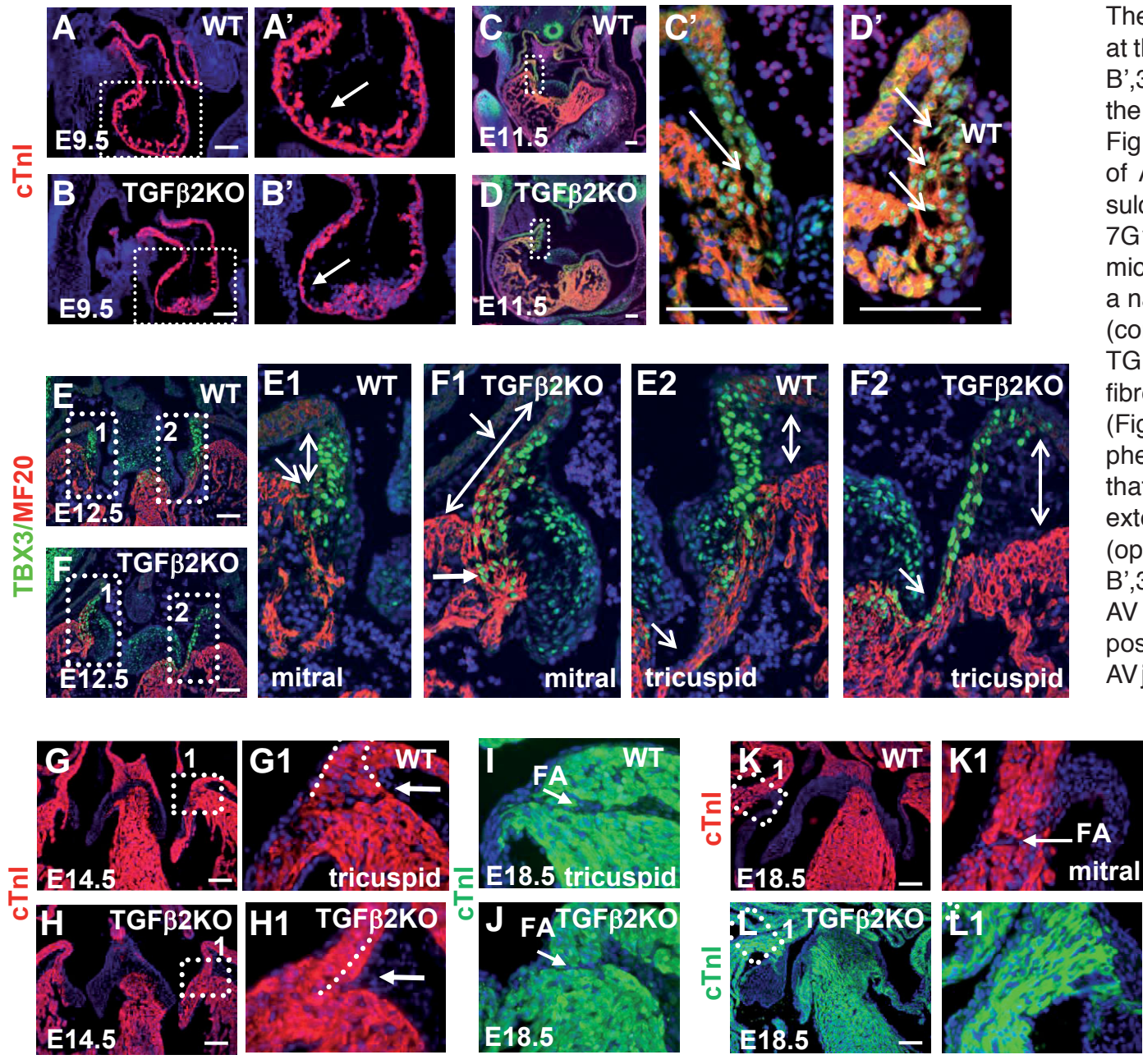
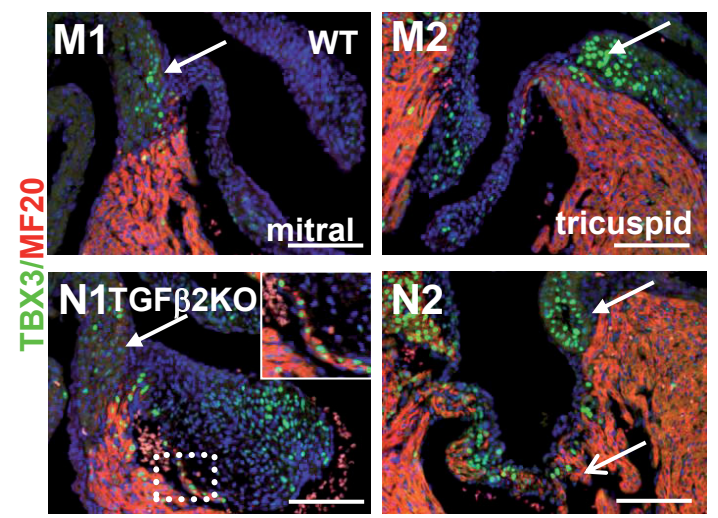
deficient mice at E12.5 (Fig. 7 E,F). The valvular myocardium is too thick at the left side (Fig. 7F1, suppl Fig. 3 B',3D') and remains present at both the right and left side (Fig. $7 \mathrm{M}, \mathrm{N}$; suppl Fig. 3B',3D'). AtE14.5, the protrusion of $\mathrm{AV}$ myocardium through the AV sulcus to the right ventricular wall (Fig. $7 G 1)$ is affected in TGF $\beta 2-$ deficient mice (Fig. 7H1), resulting at E18.5 in a narrow roof of the annulus fibrosis (compare Fig. 7J with $7 \mathrm{I})$. In another TGF $\beta 2$-deficient embryo the annulus fibrosis has not formed at the left side (Fig. 7L1). Analysis of the molecular phenotype of the AV region showed that at the left side the MF20 staining extended too far in AV myocardium (open arrow in Fig. 7E1; suppl. Fig. 3 B',3D'). At the right side at E12.5, the $\mathrm{AV}$ opening is very small and a Tbx3 positive gully covers most of the right AV junction (Fig. 7 E2,F2). The MF20+ valvular myocardium does not show downregulation of $\mathrm{Tbx} 3$ on the left side (closed arrow in Fig. 7F1, 7N1 (inset)). On the other hand, the extensive valvular myocardium of the tricuspid valve that remains, hardly

Fig. 7. Myocardial remodeling defects in TGF $\beta 2$-deficient mice. cTnl staining (red) at E9.5 shows defective trabeculae formation in a TGF $\beta 2$-deficient mouse (A,B). Tbx3 (green)/MF20 (red) staining show an increased number of spaces between inner and outer layers of AV myocardium at E11.5 (C,D) and defective myocardial phenotypes at E12.5 in TGF 32 -deficient mice (E,F). cTnl (red) staining shows absence of myocardial protrusion at the right $A V$ sulcus at $E 14.5(\mathbf{G}, \mathbf{H})$ resulting at $E 18.5$ in disrupted morphology of the right AV myocardium (1.J; cTnl is green). cTnl staining shows defective annulus fibrosis formation at the left AV myocardium in a TGF $\beta 2$-deficient mouse $\mathbf{( K , L )}$ and persistence of valvular myocardium (M,N). Tbx3 (green)/MF20 (red) staining show expression of Tbx3 in the left valvular myocardium and absence of Tbx 3 expression in the left MF20- myocardium of a TGF $\beta 2$-deficient mouse (M1;N1). Scalebar, $100 \mu \mathrm{m}$. 
E10.5 E12.5 E13.5 Left ventral side

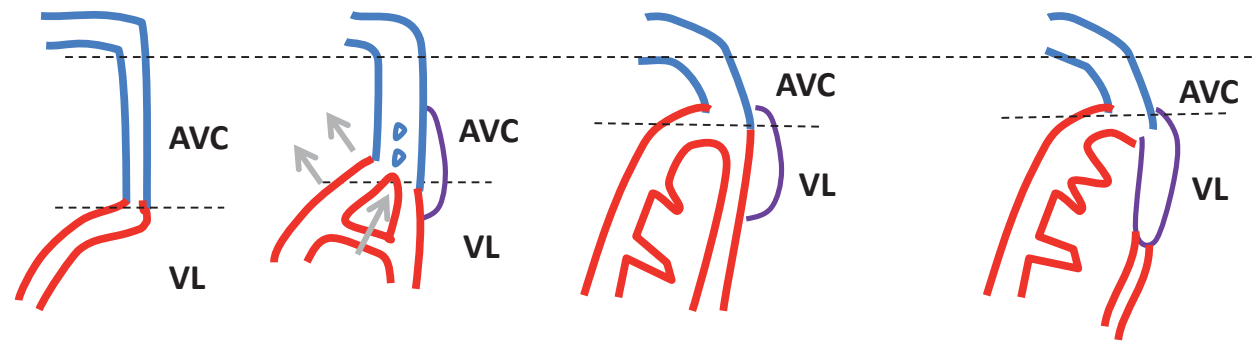

E18.5

Fig. 8. Schematic representation depicting the differential morphological changes of the left and right atrioventricular myocardium. The clearest difference between the mophological processes of the left and right AV myocardium are seen between the left ventral side and the right dorsal sides of the AV myocardium. Blue:MF20-myocardium; red:MF20+ myocardium; purple: lateral cushion. The left AV myocardium splits resulting in the positioning of the lateral cushion in the ventricular lumen (VL) and shortening of the morphological $A V C$. The right $A V$ myocardium, which will harbor the right lateral cushion, becomes positioned in the ventricular lumen by folding of the right ventricular myocardium. Protrusion of the MF20- myocardium (arrow) through the subepicardium towards the right ventricle results in reorientation of the MF20-AV myocardium, which becomes the roof of the forming annulus fibrosis (AF).

expresses Tbx3 (open arrow in Fig. 7N2). In a TGF 32 -deficient embryo of E18.5, the Tbx3 expression in MF20- AV myocardium is downregulated at the left side (arrow in Fig. 7N1), but not at the right side (arrow in Fig. 7N2). Together these observations implemented into our model reveal side specific defects including morphological defects related to myocardial remodeling, disruption of the specific molecular phenotypes of the distinct $\mathrm{AV}$ regions, defective removal of valvular myocardium and disrupted formation of the annulus fibrosis, suggesting a role for TGF $\beta 2$ in the remodeling of the early myocardium.

\section{Discussion}

In this study, we show for the first time that the formation of spaces between the inner and outer myocardial layers sets the stage for the formation of the trabeculae and the positioning of endocardial and left lateral cushions into the ventricular lumen. By delamination from AV and not from ventricular myocardium the positioning of the cushions into the ventricular lumen is achieved. For the tricuspid lateral cushion this is achieved not by delamination, but by folding of the right ventricular wall. We show that the remodeling of the right AV myocardium shows previously not reported differences with the left AV myocardium (Fig. 8). Removal of valvular myocardium, which harbors a distinct molecular phenotype, involves a second wave of delamination.

\section{Trabeculation}

The formation of the trabeculae in mice is initiated around E9.0 (Chen et al., 2004) and suggested to be the result of buckling of the myocardium in response to compression along its longitudinal axis (Sedmera et al., 2000). We show that trabeculation starts at E8.5 with the formation of spaces between the inner and outer myocardial layer similar to chicken (Icardo and Fernandez-Teran, 1987). The subsequent disengagement of the inner myocardial layer appears to be achieved by invasion of endocardial cells (Fig. 1D"', I). In the zebrafish, the ventricular wall myocardium is mono-layered and therefore, no spaces can be formed in this myocardial layer. Trabeculation is initiated by protrusion of myocardial cells out of this mono-layered myocardium (Liu et al., 2010), which might also contribute to trabeculae formation in mouse (blue arrowhead in Fig. 1C'). We observed that during the first days of trabeculae formation (E8.5-E10.5) the diameter of the ventricular lumen does not change, whereas the trabeculae become longer, indicating that the outward growth of the outer myocardial layer directs the lengthening of the early trabeculae. We observed abnormal formation of trabeculae in a TGF $\beta 2$-deficient embryo of E9.5, indicating a role for TGF $\beta 2$ in this process. Several other mutant mice also show differential trabeculation defects, supporting the presence of several stages in trabeculae formation. In some mouse mutants trabeculae form, but their growth is defective (Chen et al., 2004; Grego-Bessa et al., 2007; Lee et al., 1995; Stankunas et al., 2008) whereas in other mouse mutants (Gassmann et al., 1995; Lickert et al., 2004; Meyer and Birchmeier, 1995; Tanaka et al., 1999) no trabeculae are formed at all due to failure of the inner layer to dissociate from the outer layer and, as a consequence, a thicker myocardial layer is formed. Mice with trabecular defects often have cushion defects as well (Chen et al., 2004; Lickert et al., 2004; Lyons et al., 1995; Tanaka et al., 1999), supporting our observation that these 2 processes are closely related.

\section{Formation of free-moveable mural leaflets}

Previous studies have proposed delamination from the ventricular wall (Lamers et al., 1995; Oosthoek et al., 1998) or protrusion of the AV myocardium (de Lange et al., 2004) as a means for the AV cushions to become free-movable leaflets in the ventricular lumen. We show here that the AV cushions delaminate from the $A V$ wall. The left AV myocardium splits into two layers with sub- 
sequent ventricularization of the outer sheet, whereas the inner (luminal) sheet, supporting the cushions, becomes positioned in the ventricular lumen. Initially, many connections consist between the luminal sheet and the ventricularized AV myocardium (outer sheet), which gives the appearance of delamination from the ventricular wall (Lamers et al., 1995; Oosthoek et al., 1998). In contrast, the right AV myocardium does not contribute to and no delamination from the right ventricular wall takes place. The ventricularization of left but not right $\mathrm{AV}$ myocardium is supported by expression of Tbx3 in left ventricular wall (this study) and lineage analysis (Aanhaanen et al., 2009).

\section{Removal of valvular myocardium occurs by delamination and apoptosis}

Removal of the valvular myocardium has been suggested to occur by several mechanisms including myocardium-to-mesenchyme transformation (Lamers et al., 1995; Oosthoek et al., 1998)., retraction (Oosthoek et al., 1998), and apoptosis (de Lange et al., 2004). Lineage analysis shows that myocardium does not contribute to valve mesenchyme (de Lange et al., 2004), negating myocardium-to-mesenchyme transformation. Our data suggest that the removal of valvular myocardium exclusively by apoptosis does not occur. The lumen-to-base removal of the myocardial sleeve at the level of the free edge and the presence of one strand of $\alpha$ SMA-negative trabeculae-like myocardium, characteristic for valvular myocardium, suggest that delamination of valvular myocardium plays a role as well. Near the attachment to the dorsal papillary muscle an interruption is seen in the myocardial sleeve of the mitral mural leaflet (see supplemental Fig. 2 B-D), similar to what is observed in human (Oosthoek et al., 1998). At E18.5, a few myocardial cells can still be found (see supplemental Fig. 2D). Although the myocardial sleeve of the tricuspid mural leaflet is thicker and remains till after birth, a similar mechanism accounts for the removal of the valvular myocardium.

\section{Molecularly distinct atrioventricular myocardial subdomains}

We have shown that the valvular myocardium is distinct from the AV myocardium by its lower expression of Tbx3, higher MF20 staining and higher versican expression. The myocardial expression of $\alpha \mathrm{SMA}$ is dynamic. Whereas before E12.5 $\alpha \mathrm{SMA}$ is expressed throughout the myocardium, after E12.5 the valvular (and Tbx3+ left ventricular) myocardium loses its $\alpha$ SMA expression. The sustained expression of $\mathrm{Tbx} 3$ in left ventricular wall after birth indicates active expression of Tbx3 in these cells rather than being the result of prolonged half life as AV myocardium ventricularizes, which would indicate a specific function for Tbx3 in these cells. Tbx3 expression is correlated with non-dissociation of cells. The most distal part of the valvular myocardium that delaminates earliest from mesenchyme expresses the lowest level of Tbx3. Furthermore, in TGF $\beta 2$-deficient mice, the valvular myocardium retains high Tbx3 expression and remains attached to valve mesenchyme. Relative high Tbx3 expression in AV myocardium, therefore, might explain the difference between the disengagement and the absence of disengagement of the inner myocardial layers of the ventricle and AVC, respectively, during initial remodeling stages.

\section{Formation of the Annulus Fibrosis}

The annulus fibrosis is formed by EPDCs that migrate through the myocardium and secrete ECM components to separate the myocardium (Kolditz et al., 2008; Wessels et al., 2012; Zhou et al., 2010). EPDCs also migrate at other levels into the myocardium, but the annulus fibrosis is formed only between the $\mathrm{Tbx} 3+/ \alpha \mathrm{SMA}+/$ MF20- and Tbx3+/ $\alpha$ SMA-/MF20+ myocardium. This indicates the presence of specific signals emanating from the two myocardia regulating annulus fibrosis formation. Disruption of the molecular phenotype of these myocardia is likely to result in defective annulus fibrosis formation, as we observed in TGF $\beta 2$-deficient mice.

The differential left/right development of the AVC myocardium and leaflets suggests differential mechanisms underlying annulus fibrosis formation. At the left side the annulus fibrosis is formed completely by the invasion of EPDCs. During the invasion of EPDCs, the cardiomyocytes bordering the future annulus fibrosis separate and change orientation (unpublished observations) and lose or lower Tbx3 expression. Only the myocardium neighboring directly the valve mesenchyme maintains Tbx3 expression (Fig. $4 \mathrm{H})$. At the right side, the roof and bottom of the annulus fibrosis are formed by a myocardial loop. As a consequence, only the most luminal part (connecting part of the loop) has to be separated. The latter involves apoptosis (Fig. 6E).

\section{Accessory pathways}

Accessory pathways of AV conductance have been postulated to result in an incomplete fusion of the AV sulcus and cushion mesenchyme (Wessels et al., 1996), due to a lack of migration of EPDCs (Kolditz et al., 2007) or to abnormal differentiation of AV myocardium (Aanhaanen et al., 2011). The accessory pathways found more distant from the annulus fibrosis, are acquired during fetal and/or postnatal life (Wessels et al., 1996). We show that at the outer border of the right annulus fibrosis, especially in the posterolateral region, MF20- myocardial cells protrude through the epicardial mesenchyme of the AV sulcus towards the ventricular myocardium enclosing EPDCs (Fig. 8). Whereas myocardial cells have been shown to protrude into endocardial cushions (Kruithof et al., 2003), protrusion of myocardial cells into epicardial mesenchyme during normal development has not been reported yet. Connections between the MF20- cells and the right ventricular myocardium are present (Fig. $3 \mathrm{H})$. We postulate that ectopic migration of cardiomyocytes through the AV sulcus through a mechanism similar as seen during development is responsible for formation of accessory pathways during fetal and/or postnatal life. In addition to valvular myocardium and left ventricle, the AV myocardium contributes also to the lower rim of the atria (Wessels et al., 1996). Atrial cells that retained their ability to cross the AV sulcus might connect with the ventricular myocardium ectopically.

\section{Conclusions}

We propose a new model in which disintegration of myocardial layers forms the basis for the formation of trabeculae, a process that is continued during the repositioning of the endocardial cushions and the mitral mural leaflet in the ventricular lumen (Fig. 1I). Moreover, we show that the development of left AV myocardium differs from the right AV myocardium (Fig. 8) explaining why specific gene disruptions only causes right sided defects (Epstein's anomaly), or different defects at left compared to right side, as relevant for TGF $\beta 2$-deficient mice.

These new insights in development of trabeculae and valve 
formation can have major implications for the interpretations of congenital heart defects in human and in genetically modified mice.

\section{Materials and Methods}

\section{Animals}

Wild type FVB mice and Transforming Growth Factor- $\beta 2$ (TGF $\beta 2$ )-deficient mice (Sanford et al., 1997) were used. All procedures were approved by the Institutional Animal Care and Use Committee of the University of Medicine and Dentistry of New Jersey. Embryos are staged by number of days after vaginal plug, with day of plug considered as day 0.5 .

\section{Histology}

Hearts were fixed overnight in $4 \%$ paraformaldehyde/PBS, dehydrated in graded ethanol series, embedded in paraffin and sectioned at $6-\mu \mathrm{m}$. Sections were deparaffinized, hydrated in graded alcohol series and boiled for 20-40 minutes in Antigen Unmasking Solution (Vector Labs, H-3300) using the pressure cooker. After rinsing in $\mathrm{H} 2 \mathrm{O}$, the sections were blocked with $5 \%$ serum in $0.1 \%$ Tween-20/PBS, followed by primary antibody incubation in blocking solution overnight in humidified chamber. The sections stained using antibodies directed against $\alpha$-smooth muscle actin ( $\alpha$ SMA, Dakocytomation), cardiac Troponin I (HyTest), sarcomeric myofilaments (MF20, Developmental Studies Hybridoma Bank, University of lowa), and Versican B (Chemicon) are incubated with Alexa-conjugated secondary antibodies (Molecular Probes) diluted in PBS for visualization. The sections stained using antibodies directed against Wilm's tumor-1 (DAKO) or Tbx3 (Santa Cruz) are subsequentially incubated with biotinylated secondary antibodies, the AB solution of the Vectastain Elite ABC Kit, the biotinylated Tyramide Signal AmplificationTM (TSA) solution of the TSA ${ }^{\text {TMBiotin System }}$ (PerkinElmer), and alexa-conjugated streptavidin (Molecular Probes) for detection. Sections were mounted with ProlOng Gold antifade reagent with Dapi (Invitrogen) to visualize the nuclei.

\section{Morphometric measurements}

The diameter of the lumen of the ventricle and the length of the trabeculae were measured in the center of the ventricle on sagittal sections. The lumen of the ventricle is defined by the absence of trabeculae. The diameter of the AVC was measured in the center of the AVC on frontal sections. A minimum of 3 animals per group were used. Results were compared using the two-tailed $t$ test and a significance level of $\mathrm{P}<0.05$.

\section{Acknowlegdements}

We thank L. Emile for expert technical assistance. This work was supported by the American Heart Association (0555840T to V.G. and 0625861 T to B.P.T.K.), the March of Dimes Birth Defects Foundation (1FY06-375 to V.G.), the Dutch Heart Foundation, the Netherlands Institute for Regenerative Medicine and Smartcare, part of the research program of the BioMedical Materials institute, co-funded by the Dutch Ministry of Economic Affairs, Agriculture and Innovation.

\section{References}

AANHAANEN W T, BOUKENS B J, SIZAROV A, WAKKER V, DE GIER-DE VRIES C, VAN GINNEKEN A C, MOORMAN A F, CORONEL R, CHRISTOFFELS V M (2011). Defective Tbx2-dependent patterning of the atrioventricular canal myocardium causes accessory pathway formation in mice. J Clin Invest 121: 534-544.

AANHAANEN W T, BRONS J F, DOMINGUEZ J N, RANA M S, NORDEN J, AIRIK R, WAKKER V, DE GIER-DE VRIES C, BROWN N A, KISPERT A, MOORMAN A F, CHRISTOFFELS V M (2009). The Tbx2+ primary myocardium of the atrioventricular canal forms the atrioventricular node and the base of the left ventricle. Circ Res 104: 1267-1274.

BARTRAMU, MOLIND GM, WISSELJ, MOHAMADA, SANFORD LP, DOETSCHMAN T, SPEER C P, POELMANN R E, GITTENBERGER-DE GROOT A C (2001). Double-Outlet Right Ventricle and Overriding Tricuspid Valve Reflect Disturbances of Looping, Myocardialization, Endocardial Cushion Differentiation, and Apoptosis in TGF-\{beta\}2-Knockout Mice. Circulation 103: 2745-2752.

BAX N A, VAN OORSCHOT A A, MAAS S, BRAUN J, VAN TUYN J, DE VRIES A A, GROOT A C, GOUMANS M J (2011). In vitro epithelial-to-mesenchymal transformation in human adult epicardial cells is regulated by TGFbeta-signaling and WT1. Basic Res Cardiol 106: 829-847.

BEN-SHACHAR G, ARCILLA R A, LUCAS R V, MANASEK F J (1985). Ventricular trabeculations in the chick embryo heart and their contribution to ventricular and muscular septal development. Circ Res 57: 759-766.

CHALLICE C E, VIRAGH S (1974). The architectural development of the early mammalian heart. Tissue Cell 6: 447-462.

CHEN H, SHI S, ACOSTA L, LI W, LU J, BAO S, CHEN Z, YANG Z, SCHNEIDER M D, CHIEN K R, CONWAY S J, YODER M C, HANELINE L S, FRANCO D, SHOU W (2004). BMP10 is essential for maintaining cardiac growth during murine cardiogenesis. Development 131: 2219-2231.

CHEN H, ZHANG W, LI D, CORDES T M, MARK PAYNE R, SHOU W (2009). Analysis of ventricular hypertrabeculation and noncompaction using genetically engineered mouse models. Pediatr Cardiol 30: 626-634.

DE LANGE F J, MOORMAN A F, ANDERSON R H, MANNER J, SOUFAN A T, DE GIER-DE VRIES C, SCHNEIDER M D, WEBB S, VAN DEN HOFF M J, CHRISTOFFELS V M (2004). Lineage and morphogenetic analysis of the cardiac valves. Circ Res 95: 645-654.

GASSMANN M, CASAGRANDA F, ORIOLI D, SIMON H, LAI C, KLEIN R, LEMKE G (1995). Aberrant neural and cardiac development in mice lacking the ErbB4 neuregulin receptor. Nature 378: 390-394.

GREGO-BESSA J, LUNA-ZURITA L, DEL MONTE G, BOLOS V, MELGAR P, ARANDILLA A, GARRATT A N, ZANG H, MUKOUYAMA Y S, CHEN H, SHOU W, BALLESTAR E, ESTELLER M, ROJAS A, PEREZ-POMARES J M, DE LA POMPA J L (2007). Notch signaling is essential for ventricular chamber development. Dev Cell 12: 415-429.

HOOGAARS W M, TESSARI A, MOORMAN A F, DE BOER P A, HAGOORT J, SOUFAN A T, CAMPIONE M, CHRISTOFFELS V M (2004). The transcriptional repressor Tbx3 delineates the developing central conduction system of the heart. Cardiovasc Res 62: 489-499.

ICARDO J M, FERNANDEZ-TERAN A (1987). Morphologic study of ventricular trabeculation in the embryonic chick heart. Acta Anat (Basel) 130: 264-274.

JENNIR, ROJAS J, OECHSLINE (1999). Isolated noncompaction of the myocardium. N Engl J Med 340: 966-967.

KOLDITZ D P, WIJFFELS M C, BLOM NA, VAN DER LAARSE A, HAHURIJ N D, LIEVENEMAH, MARKWALD RR, POELMANNRE, SCHALIJ M J, GITTENBERGERDE GROOT A C (2008). Epicardium-derived cells in development of annulus fibrosis and persistence of accessory pathways. Circulation 117: 1508-1517.

KOLDITZ D P, WIJFFELS M C, BLOM N A, VAN DER LAARSE A, MARKWALD R R, SCHALIJ M J, GITTENBERGER-DE GROOT A C (2007). Persistence of functional atrioventricular accessory pathways in postseptated embryonic avian hearts: implications for morphogenesis and functional maturation of the cardiac conduction system. Circulation 115: 17-26.

KRUITHOF B P, DUIM S N, MOERKAMP A T, GOUMANS M J (2012). TGFbeta and BMP signaling in cardiac cushion formation: Lessons from mice and chicken. Differentiation 84: 89-102.

KRUITHOF B P, VAN DEN HOFF M J, WESSELS A, MOORMANA F (2003). Cardiac muscle cell formation after development of the linear heart tube. Dev Dyn227:1-13.

LAMERS W H, VIRAGH S, WESSELS A, MOORMAN A F, ANDERSON R H (1995). Formation of the tricuspid valve in the human heart. Circulation 91: 111-121.

LEE K F, SIMON H, CHEN H, BATES B, HUNG M C, HAUSER C (1995). Requirement for neuregulin receptor erbB2 in neural and cardiac development. Nature 378: 394-398.

LICKERT H, TAKEUCHI J K, VON BOTH I, WALLS J R, MCAULIFFE F, ADAMSON $S$ L, HENKELMAN R M, WRANA J L, ROSSANT J, BRUNEAU B G (2004). Baf60c is essential for function of BAF chromatin remodelling complexes in heart development. Nature 432: 107-112.

LIU J, BRESSAN M, HASSEL D, HUISKEN J, STAUDT D, KIKUCHI K, POSS K D, MIKAWA T, STAINIER D Y (2010). A dual role for ErbB2 signaling in cardiac trabeculation. Development 137: 3867-3875.

LYONS I, PARSONS L M, HARTLEY L, LI R, ANDREWS J E, ROBB L, HARVEY R P (1995). Myogenic and morphogenetic defects in the heart tubes of murine embryos lacking the homeo box gene Nkx2-5. Genes Dev 9: 1654-1666. 
MEYER D, BIRCHMEIER C (1995). Multiple essential functions of neuregulin in development. Nature 378: 386-390.

OOSTHOEK P W, WENINK A C, VROLIJK B C M, WISSE L J, DERUITER M C POELMANN R E, GITTENBERGER-DE GROOT A C (1998). Development of the atrioventricular valve tension apparatus in the human heart. Anat Embryol 198: $317-329$

PEREZ-POMARES J M, PHELPS A, SEDMEROVA M, CARMONA R, GONZALEZIRIARTE M, MUNOZ-CHAPULI R, WESSELS A (2002). Experimental studies on the spatiotemporal expression of WT1 and RALDH2 in the embryonic avian heart: a model for the regulation of myocardial and valvuloseptal development by epicardially derived cells (EPDCs). Dev Biol 247: 307-326.

PIERPONT M E, BASSON C T, BENSON D W, JR., GELB B D, GIGLIA T M, GOLDMUNTZ E, MCGEE G, SABLE C A, SRIVASTAVA D, WEBB C L (2007). Genetic basis for congenital heart defects: current knowledge: a scientific statement from the American Heart Association Congenital Cardiac Defects Committee, Council on Cardiovascular Disease in the Young: endorsed by the American Academy of Pediatrics. Circulation 115: 3015-3038.

SANFORD L P, ORMSBY I, GITTENBERGER-DE GROOTA C, SARIOLA H, FRIEDMANR, BOIVIN G P, CARDELLE L, DOETSCHMANT (1997). TGFbeta2 knockout mice have multiple developmental defects that are non-overlapping with other TGFbeta knockout phenotypes. Development 124: 2659-2670.

SEDMERA D, PEXIEDER T, VUILLEMIN M, THOMPSON R P, ANDERSON R H (2000). Developmental patterning of the myocardium. Anat Rec 258: 319-337.
SEDMERA D, THOMAS P S (1996). Trabeculation in the embryonic heart. Bioessays 18: 607.

STANKUNAS $K$, HANG C T, TSUN Z Y, CHEN H, LEE N V, WU J I, SHANG C, BAYLE J H, SHOU W, IRUELA-ARISPE M L, CHANG C P (2008). Endocardial Brg1 represses ADAMTS1 to maintain the microenvironment for myocardial morphogenesis. Dev Cell 14: 298-311.

TANAKAM, CHEN Z, BARTUNKOVAS, YAMASAKI N, IZUMO S (1999). The cardiac homeobox gene Csx/Nkx2.5 lies genetically upstream of multiple genes essentia for heart development. Development 126: 1269-1280.

WESSELS A, MARKMAN M W, VERMEULEN J L, ANDERSON R H, MOORMAN A F, LAMERS W H (1996). The development of the atrioventricular junction in the human heart. Circ Res 78: 110-117.

WESSELS A, VAN DEN HOFF M J, ADAMO R F, PHELPS A L, LOCKHART M M SAULS K, BRIGGS L E, NORRIS R A, VAN WIJK B, PEREZ-POMARES J M DETTMAN R W, BURCH J B (2012). Epicardially derived fibroblasts preferentially contribute to the parietal leaflets of the atrioventricular valves in the murine heart. Dev Biol 366: 111-124.

ZHOU B, MAQ, RAJAGOPALS, WU S M, DOMIAN I, RIVERA-FELICIANO J, JIANG D, VON GISEA, IKEDAS, CHIEN K R, PUWT (2008). Epicardial progenitors contribute to the cardiomyocyte lineage in the developing heart. Nature 454: 109-113.

ZHOU B, VON GISE A, MA Q, HU Y W, PU W T (2010). Genetic fate mapping demonstrates contribution of epicardium-derived cells to the annulus fibrosis of the mammalian heart. Dev Biol 338: 251-261. 


\section{Further Related Reading, published previously in the Int. J. Dev. Biol.}

Building the vertebrate heart - an evolutionary approach to cardiac development José M. Pérez-Pomares, Juan M. González-Rosa and Ramón Muñoz-Chápuli

Int. J. Dev. Biol. (2009) 53: 1427-1443

http://dx.doi.org/10.1387/ijdb.072409jp

In vivo forced expression of myocardin in ventricular myocardium transiently impairs systolic performance in early neonatal pig heart Mario Torrado, Alberto Centeno, Eduardo López and Alexander T. Mikhailov

Int. J. Dev. Biol. (2009) 53: 1457-1467

http://dx.doi.org/10.1387/ijdb.072366mt

Epithelial-Mesenchymal Transitions in development and disease: old views and new perspectives

M. Angela Nieto

Int. J. Dev. Biol. (2009) 53: 1541-1547

http://dx.doi.org/10.1387/ijdb.072410mn

Efficient Cre-mediated deletion in cardiac progenitor cells conferred by a 3'UTR-iresCre allele of the homeobox gene Nkx2-5

Edouard G Stanley, Christine Biben, Andrew Elefanty, Louise Barnett, Frank Koentgen, Lorraine Robb and Richard P Harvey

Int. J. Dev. Biol. (2002) 46: 431-439

http://www.intjdevbiol.com/web/paper/12141429

Functional analysis of the TGFbeta receptor/Smad pathway through gene ablation in mice M J Goumans and C Mummery

Int. J. Dev. Biol. (2000) 44: 253-265

http://www.intjdevbiol.com/web/paper/10853822

5 yr ISI Impact Factor $(2011)=2.959$
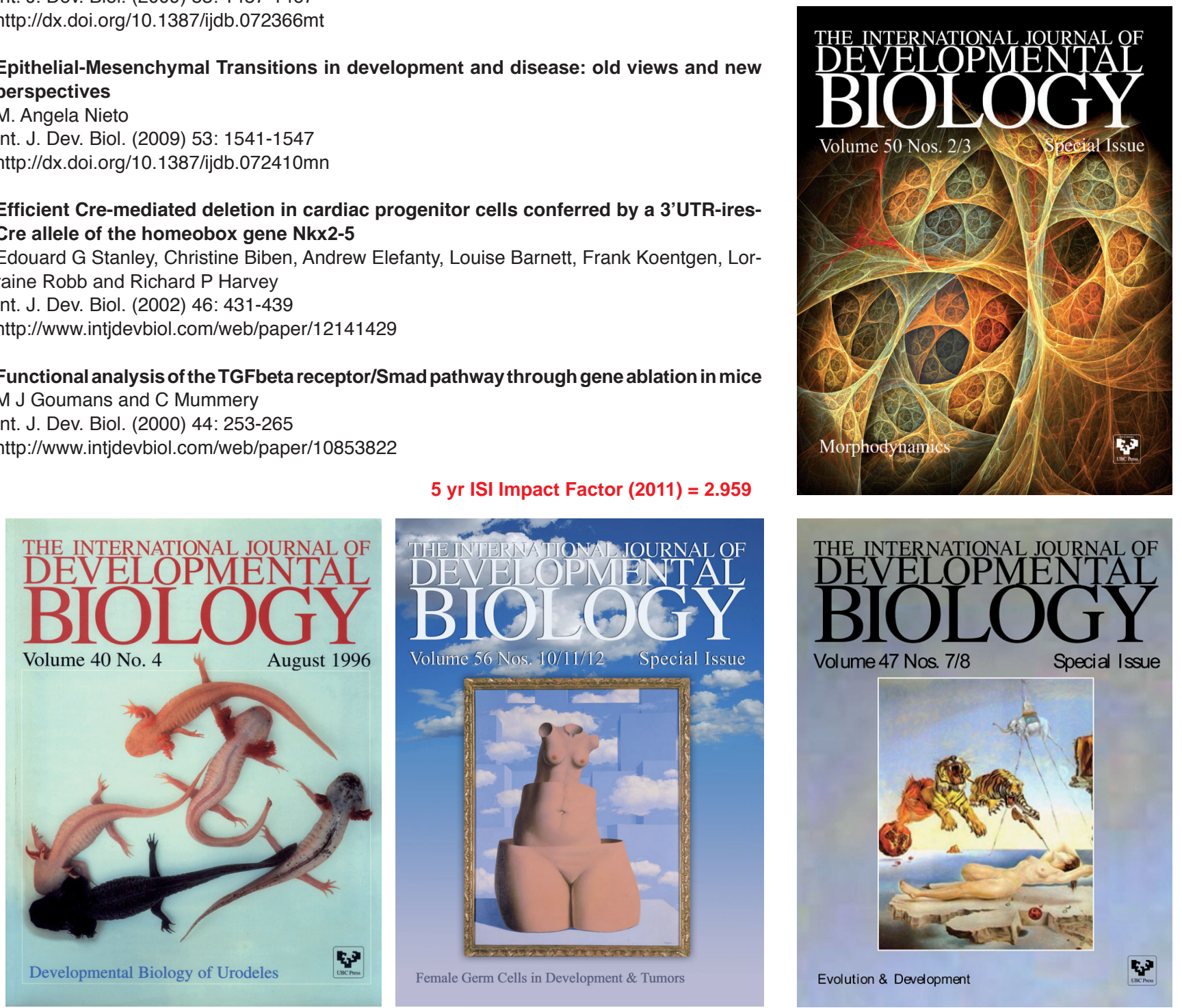

Volume 47 Nos. $7 / 8$

Special Issue

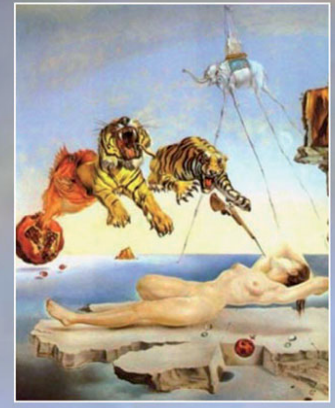

Evolution \& Development 